\title{
Addressing the Indirect Trauma of Social Work Students in Intimate Partner Violence (IPV) Field Placements: A Framework for Supervision
}

\author{
Sarah Tarshis $^{1}$ [D $\cdot$ Stephanie L. Baird ${ }^{1}$
}

Published online: 6 September 2018

○) Springer Science+Business Media, LLC, part of Springer Nature 2018

\begin{abstract}
Intimate partner violence (IPV), which encompasses physical, sexual, financial, and/or emotional abuse in a dating or partner relationship, is a serious and prevalent issue that social workers respond to. IPV can create varying degrees of trauma among survivors, such as posttraumatic stress, hypervigilance, flashbacks, anxiety, and depression. Social workers play a key role in helping survivors of IPV recover from this trauma, which in turn puts them at risk of experiencing indirect trauma such as vicarious trauma, secondary traumatic stress, and compassion fatigue. Unfortunately, social work students are at an even greater risk of experiencing forms of indirect trauma as they are often unprepared to cope with exposure to trauma. While there have been studies on mitigating indirect trauma of practitioners working with survivors of IPV, there is a dearth of research on the experiences of social work students in IPV field placements, and on the crucial role of supervision in supporting students to cope with exposure to trauma. In response, this paper: (1) defines indirect trauma and trauma-related concepts; (2) proposes a conceptual framework for supervision that detects and addresses indirect trauma among social work students in field placements; and (3) illustrates this framework with case examples of MSW students within IPV field placements. Implications for social work practice are discussed throughout the paper.
\end{abstract}

Keywords Intimate partner violence $\cdot$ Supervision $\cdot$ Indirect trauma $\cdot$ Secondary trauma $\cdot$ Vicarious trauma $\cdot$ Field placement

\section{Introduction}

There are nearly 2000 intimate partner violence (IPV) organizations across the United States providing support services to countless survivors of violence each year (National Network to End Domestic Violence 2016). Within these IPV organizations, social workers play a key role, assisting survivors who are coping with the aftermath of violence (Baird and Jenkins 2003; Bell 2003; Connor et al. 2012). Social work students also play a key role in these IPV organizations, providing support for survivors of IPV while completing their social work field training.

Sarah Tarshis

sarah.tarshis@mail.utoronto.ca

Stephanie L. Baird

stephanie.baird@mail.utoronto.ca

1 Factor-Inwentash Faculty of Social Work, University of Toronto, 246 Bloor Street West, Toronto, ON M5S 1A1, Canada
IPV is defined as the physical, sexual, financial, and/or emotional abuse inflicted by intimate or dating partners, during or after a relationship (Center for Disease Control 2016). Impacts of IPV can include varying degrees of trauma including posttraumatic stress disorder (PTSD), hypervigilance, flashbacks, anxiety and depression among survivors (Cunningham 2003; Helms et al. 2010). A systematic review of the IPV and PTSD literature reported a sevenfold increase in the likelihood of PTSD for women who have experienced IPV (Trevillion et al. 2012), with survivors who experience trauma often requiring specialized services to treat the effects of abuse (Slattery and Goodman 2009; Sommer 2008).

Social workers who do not have adequate trauma training may also unknowingly experience forms of indirect trauma (e.g., secondary trauma, vicarious trauma, compassion fatigue) (Harr and Moore 2011; Knight 2013; Pill et al. 2017). Indirect trauma is defined as the negative consequences associated with working with trauma survivors, such that the emotional well-being of practitioners becomes damaged through their therapeutic work with 
trauma survivors (Ben-Porat and Itzhaky 2011). Prolonged exposure to and lack of knowledge of the effects of indirect trauma can also lead to burnout, or the decision to leave the field (Baird and Jenkins 2003; Chouliara et al. 2009).

Supervision can provide social workers with strategies in dealing with the adverse effects of exposure to trauma (Bell et al. 2003; Cunningham 2003). In some cases, supervision has been shown to serve as a protective factor for indirect trauma (Carello and Butler 2015). However, supervision can also be a risk factor for indirect trauma in situations when supervisory interactions are not beneficial (Didham et al. 2011; Litvack et al. 2010). Supervisors may also overlook or miss the signs of indirect trauma of their supervisees. In some cases, social workers who disclose indirect trauma to supervisors may be perceived as weak or vulnerable which can further stigmatize their experiences (Goldblatt and Buchbinder 2003).

Exposure to trauma survivors can challenge the emotional stability of the most experienced of social workers, but is often even more challenging for students without appropriate supervision, coping skills, or strategies (Breckenridge and James 2010; Litvack et al. 2010). Newer therapists are at greater risk of vicarious trauma and burnout than those who have been in the field for several years (Bride et al. 2007). While there have been numerous studies on the indirect trauma of social work practitioners (Bride 2004; Canfield 2005; Cunningham 2003; Connor et al. 2012; Figley 1983; Rasmussen 2012), emerging research on the effects of indirect trauma of social work students (Abrams and Shapiro 2014; Adams and Riggs 2008; Litvack et al. 2010; Tosone et al. 2012), there is a dearth of research exploring the role of indirect trauma among social work students in IPV field placement settings (Goldblatt and Buchbinder 2003; Harr and Moore 2011), And, to the best of our knowledge, there is no literature that outlines a framework for addressing indirect trauma in supervision specifically for social work students in IPV field placements.

In response to concerns about the dearth of research investigating supervision and ways to mitigate indirect trauma among students in IPV field placements, this paper: (1) examines key concepts of indirect trauma and traumarelated constructs; (2) presents a conceptual framework integrating social ecological (Bookchin 1980, 1982; Heise 1998) and trauma-informed underpinnings (Courtois 2018; Knight 2018) to help supervisors address indirect trauma of social work students in IPV field placements; and (3) illustrates this framework of supervision with case examples of MSW students within IPV field placements. After illustrating this framework of supervision with MSW case examples, we conclude with specific recommendations for applying this framework among field placements.

\section{Method}

A broad search of peer-reviewed literature related to supervision, indirect trauma, and social work students using PsycINFO, Sociological Abstracts, EBSCOhost, ERIC, PubMed, and Social Work Abstracts was undertaken. Manual searches of the specific social work journals (e.g., Clinical Social Work Journal, The Clinical Supervisor) were also conducted. Our search criteria were limited to studies published in English across a 30 year time frame between 1988 and 2018. In addition, relevant works on supervision shared by colleagues and practitioners were also incorporated, as well as significant studies identified using Google Scholar. Variations on the following terms were used in the search: intimate partner violence/ IPV, domestic violence/DV, supervision/supervisor, field learning/placement, social work student/intern, indirect trauma-related terms (vicarious trauma, secondary trauma, compassion fatigue) and education/training. The authors also screened for additional studies through bibliographic referencing. To improve the rigor of the analytical process, all potential articles were evaluated by two independent reviewers to ensure that they met eligibility criteria.

A total of 1080 references were retrieved, of which 167 articles were identified as eligible during pre-screening. After the removal of duplicates, title and abstract review, 34 articles remained for full text review. The authors identified 20 articles that met criteria for the review of literature which enhanced our understanding of indirect trauma (e.g., secondary trauma, vicarious trauma) of social work students in IPV field placements. Articles which focused on the indirect trauma of social work students (e.g., Agllias 2012; Goldblatt and Buchbinder 2003; Harr and Moore 2011; Hesse 2002; Litvack et al. 2010), were read along with key trauma-informed (e.g., Courtois 2018; Harris and Fallot 2001; Knight 2018; Tosone et al. 2012) and supervision literature (e.g., Ben-Porat and Itzhaky 2011; Bogo and McNight 2006; Bogo et al. 2011; Kadushin 1992; Peled-Avram 2017), to develop a preliminary framework for supervisors of students in IPV field placements.

\section{Key Constructs of Trauma and Indirect Trauma}

\section{Differentiating PTSD and Trauma}

Within the literature, different terms are often used to discuss trauma. The term trauma is used more broadly to refer to a response to a traumatic event, which could include physical or mental health responses (Abrams and Shapiro 
2014). Traumatic events (e.g., IPV, sexual assault, war, natural or human made disasters) are emotionally overwhelming and often involve threats and/or actual actions that cause serious emotional or physical injury. Responses to traumatic events can range from causing minor disruptions to more severe and debilitating responses which can impact daily functioning (e.g., ability to work, relationships with others). Post-traumatic stress disorder (PTSD) is recognized as a psychiatric disorder and mental health diagnosis which is experienced as a reaction to a traumatic event (Jones et al. 2001). Due to the recognition that signs of trauma may be broader than those fitting diagnostic criteria of PTSD, and that many people who experience traumatic events may not receive a formal diagnosis, the term trauma will be used throughout this paper.

\section{Forms of Indirect Trauma}

Social workers and other mental health service providers frequently come into contact with those who have experienced trauma. These professionals are often in close contact with trauma survivors and risk their own emotional disruptions (Bride et al. 2007). As a result, the consequence of these repeated contacts may lead to experiences of indirect trauma (Figley 1995). Specific manifestations of indirect trauma include secondary trauma, vicarious trauma, and compassion fatigue (Knight 2015). Experiences of indirect trauma are described as reactions to the emotional and psychological demands of working with trauma survivors (Baird and Jenkins 2003). While secondary trauma, vicarious trauma, and compassion fatigue share many characteristics and are often used interchangeably in the literature (Harr and Moore 2011), it is important to distinguish each term. Each of these terms are distinct and have different ways of being measured.

\section{Secondary Trauma}

Figley (1995) originally defined secondary trauma as the behaviors and emotions that result from knowing or hearing about a traumatizing event, and the stress associated with helping or wanting to help those who have been traumatized.

Signs of secondary trauma are similar to those of PTSD and include flashbacks, nightmares, intrusive thoughts, dissociation, and numbing (Byrne et al. 2006; Canfield 2005). Left unrecognized or unattended, secondary trauma can eventually lead to burnout, or the decision to leave the field, among other risks (Chouliara et al. 2009). Secondary trauma has a quicker onset and may be temporary while vicarious trauma is more gradual and can be chronic (Jenkins and Baird 2002).

\section{Compassion Fatigue}

Figley $(1995,2002)$ later renamed secondary trauma to compassion fatigue as a term that is less stigmatizing (Figley 2002; Jenkins and Baird 2002), although the terms secondary trauma and compassion fatigue are both still used in the literature. Compassion fatigue can occur as a result of ongoing or cumulative exposure to the suffering and distress of others, which could include working with those who have experienced trauma and/or other negative events in their lives (Figley 1995). Compassion fatigue can be further problematic without proper support (e.g., supervision, peer-support, family) (Harr and Moore 2011). Compassion fatigue can also reduce one's ability and interest in being empathic towards clients. Harr and Moore (2011) describe compassion fatigue as the "inability to concentrate, decreased selfesteem, apathy, preoccupation with trauma, perfectionism, rigidity, or, in extreme cases, thoughts of harming self or others" (p. 352). Compassion fatigue can also create anxiety, fear, depression, helplessness, and powerlessness, which can impact one's worldview and undermine personal and work relationships (Berzoff and Kita 2010; Harr and Moore 2011; Jenkins and Baird 2002). Those without proper selfcare and less social support are more susceptible to compassion fatigue.

\section{Vicarious Trauma}

Vicarious trauma involves an emotional and psychological transformation or shift due to empathic engagement with trauma survivors (Baird and Jenkins 2003; Pearlman and Saakvitne 1995). The experience of vicarious trauma can cause changes in identity, view, spirituality, beliefs about self/others, and intimate relationships (Pearlman and Saakvitne 1995). Signs can include feeling powerless, feeling 'infected' by trauma, feeling hopelessness or depression, experiencing increased pessimism or cynicism, and viewing life or the world as an unsafe place (Jenkins and Baird 2002). There also may be additional changes in social behaviors (e.g., social withdrawal, feeling estranged from friends/ family) and difficulties in separating professional life from personal life. Effects of vicarious trauma can be overwhelming and long-term and can lead to decreased self-care and absenteeism from work (Cunningham 2003).

\section{Burnout}

Burnout is seen as having many similar characteristics as compassion fatigue. However, burnout can be seen in a variety of workplace settings and is not necessarily related to working with those who are suffering or traumatized, and is seen to develop over a long period of time (Ben-Porat and Itzhaky 2011). Burnout can be related to a lack of recognition for one's 
work or role in the workplace, conflict between one's values and organizational practices, or lack of input into organizational decisions (Bell et al. 2003). Maslach (1982) described three dimensions of burnout: (1) emotional exhaustion; (2) depersonalization (e.g., negative attitude towards clients, personal detachment, loss of ideals); and (3) reduced sense of personal accomplishment, meaning and commitment to field. Burnout has been conceptualized as a process rather than a condition or state, and some have theorized that it progresses sequentially through each of these dimensions (Bell et al. 2003). Signs manifest gradually, through emotional exhaustion, cynicism, detachment from work, lack of sense of accomplishment and effectiveness at work. This process is more directly affected by work itself, and occurs gradually, where secondary trauma can emerge suddenly (Kulkarni et al. 2013).

\section{Shared Trauma}

When practitioners experience a traumatic event that impacts them both personally and professionally, this experience is referred to as shared trauma (Tosone et al. 2012). Shared trauma has been reported by practitioners who personally experience events such as natural disasters, mass violence, and war (e.g., Hurricane Katrina, 9/11, and the Gaza war) (Baum 2013; Tosone et al. 2003, 2014) and work with clients who also experienced these traumatic events. Tosone et al. (2012) state that shared trauma "contain[s] aspects of primary and secondary trauma, and more accurately describes the extraordinary experiences of clinicians exposed to the same community trauma as their clients" (p. 231).

\section{Trauma-Informed Practice}

Using a trauma-informed approach means that practitioners recognize the ways in which past experiences of trauma can impact clients in the present, including an awareness of the ways in which past trauma may impact client's problems that are not presented as trauma (Harris and Fallot 2001; Knight 2015). There are five principles of trauma-informed practice which are applicable to working with survivors of IPV. These principles include ensuring safety of the survivor, validating and normalizing the survivor's experiences, supporting and collaborating with the survivor to better understand past experiences, prioritizing empowerment and choice over their lives, and ensuring that the survivor understands the connections between previous trauma and the impact on their present lives (Courtois 2018; Knight 2018).

\section{Conceptual Framework}

This paper integrates tenets from a social ecological framework (Bookchin 1980, 1982; Heise 1998) and trauma-informed practices (Courtois 2018; Knight 2018) to build a framework for supervising social work students in IPV field placements who are experiencing indirect trauma. A social ecological approach is frequently utilized in social work practice and IPV research to explore an individual's complex relationships to their environment (CDC 2018; Logie et al. 2014; Ungar 2002). Similar to the ecological perspective (Bronfenbrenner 1979), social ecology emphasizes paying close attention to the social, psychological, institutional, and cultural contexts of the individual-environment relationship (Stokols et al. 2013).

The proposed four level framework (individual, relational, community/organizational, structural) considers both how factors can pose as risks for indirect trauma, and how interventions can address each level. Each level overlaps; see Fig. 1 to demonstrate how levels are interconnected with one another and how interventions should address each level. In the context of indirect trauma, a social ecological model can help explain behaviors and experiences of students at many levels: intrapersonal/psychological (e.g., individual behavior, attitudes, responses), relational (social relationships, supervisory relationships, available social support), community/organizational (e.g., IPV organizations, academic institutions, access to consistent, quality supervision), and structural (indirect trauma stigma, awareness of indirect trauma) (Baral et al. 2011).

Given the exposure to trauma when working with survivors of IPV, and the possibility of indirect trauma of social work students, trauma-informed practices can help support students during their field learning (Berger et al. 2017). A trauma-informed framework encourages supervisors to impart knowledge of trauma, build a strong supervisor/ supervisee relationship while maintaining professional boundaries, assess and detect student vulnerability to forms of indirect trauma, and encourage self-care (Knight 2018). Thus, the application of trauma-informed supervision can give social worker students the valuable skills needed to treat trauma survivors and manage their own emotional responses (Knight 2018; LeGeros and Savage Borne 2012).

While trauma-informed supervision requires a comprehensive understanding of trauma, the supervisor must also possess core clinical supervisory skills. Trauma-informed supervision encourages collaboration, active learning, and professionalism (e.g., setting and maintaining boundaries, ensuring supervision does not become therapy) (Goodman et al. 2016). Without adequate training and preparation, 


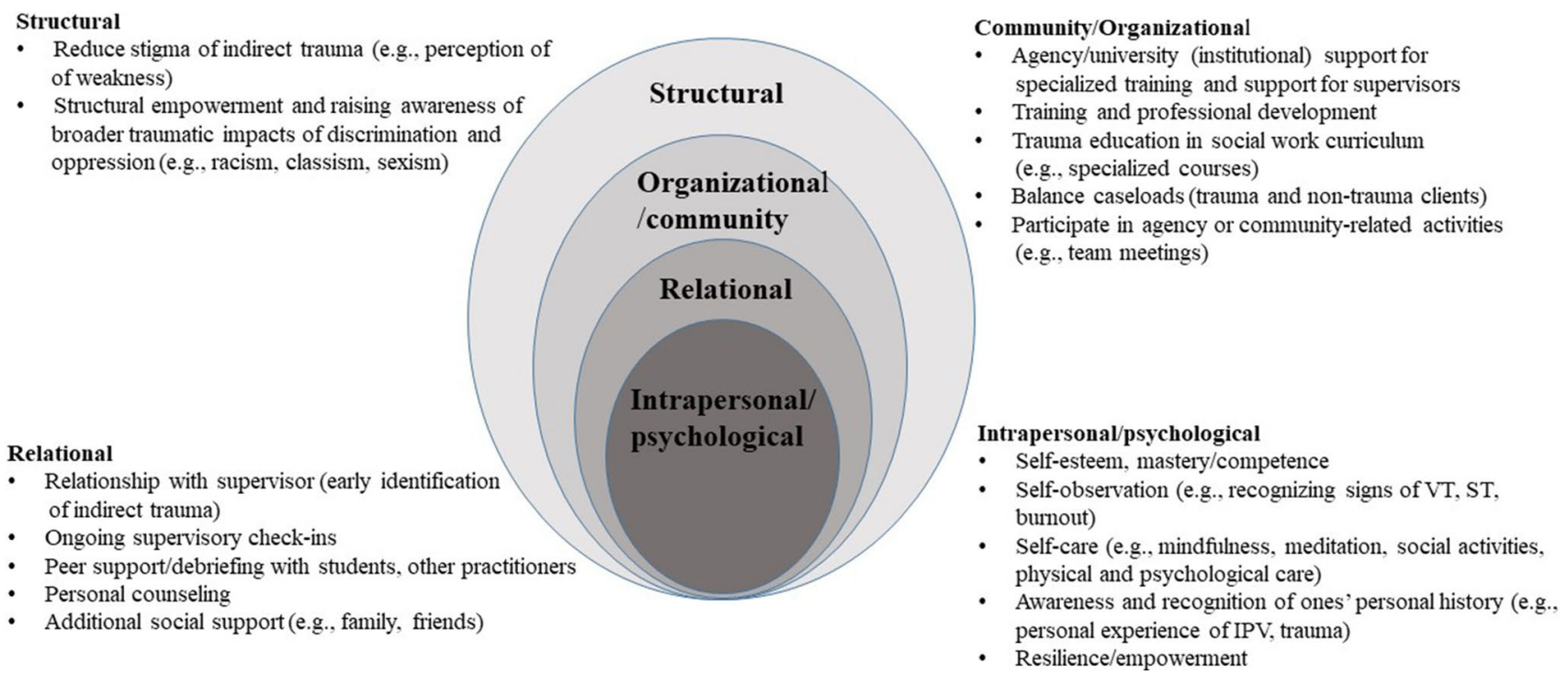

Fig. 1 A framework for addressing indirect trauma of social work students in IPV field placements

supervisors who lack an understanding of trauma and knowledge of the primary principles of trauma-informed practice (safety, trust, collaboration, choice, empowerment) risk turning supervision into therapy (Knight 2018).

This integrated conceptual framework provides general guidelines for supervising social work students in IPV field placements, addressing trauma from a broad lens that recognizes multilevel contributions to indirect trauma. In addition, this framework provides recommendations to discuss and educate students about indirect trauma in non-stigmatizing ways, as well as concrete self-care strategies (e.g., identifying potential triggers, developing strategies for coping and support, addressing physical and emotional safety) to help students cope with exposure to trauma within IPV settings.

\section{Intrapersonal/Psychological}

Beginning at the intrapersonal and psychological level for each student, supervisors can address exposure to trauma, regardless of what students disclose to them.

\section{Recognizing Vulnerability to Indirect Trauma}

Supervisors can recognize and detect student vulnerability to indirect trauma, while also focusing on their resilience (Berger et al. 2017). At the early stages of field learning, supervisors can check in on how students are coping, and can also specifically assess students for indirect trauma by utilizing assessment tools and checklists (Bride et al. 2007). Students can then learn to do self-assessments, a skill which will help them assess for their own indirect trauma going forward in their careers (Bride et al. 2007).

\section{Students' Past Traumatic Experiences}

Students may have their own personal histories with trauma or violence which have led them to the field of social work, and specifically to IPV work (Courtois 2018). Students may choose to work in the IPV field due to their own previous experiences of IPV or those of family members, resulting in a shared traumatic experience with their clients (Frey et al. 2017). Students with previous or unresolved trauma may struggle in sessions when clients recount particular details of abuse, which may create strong reactions that impede their ability to focus in sessions. This response could put both the student and the client in a vulnerable position, with the student becoming "too close" to the work (Bell 2003). Students who are motivated to enter the field of IPV a result of their own experiences with trauma need to be especially aware of their own countertransference and maintain professional boundaries (Harr and Moore 2011). In particular, students may not yet understand or be aware of their experiences of shared trauma and how they can impact them and their work (Dekel and Baum 2009; Tosone et al. 2012).

While it may be important for supervisors to be aware of any history of trauma that may impact students' work with clients, this can sometimes be difficult for students to disclose. Supervisors can help with this by creating an atmosphere in which past traumatic experiences are normalized and viewed as a form of resilience, rather than pathologized. Supervisors can also educate students about the ways in which a practitioner's personal history (e.g., experiences of abuse), current experiences, personality, and disposition contribute to their experiences of indirect trauma (Tosone et al. 2012). By raising topics such as past trauma in ways 
that educate and normalize, students can be made aware of the potential for indirect trauma and ways to respond without having to disclose their personal experiences to their supervisors.

\section{Addressing "Psychological Shattering of One's Worldview"}

This occurs when one's belief that the world as a safe place where individuals are compassionate to each other is replaced by a belief that the world is an unsafe place where people cause harm to one another. This experience leaves individuals disempowered and helpless, a common reaction to trauma (Goldblatt and Buchbinder 2003; Janof-Bulman 1992; Straussner and Calnan 2014). Supervisors can address this with students by discussing this phenomenon in supervision, exploring this concept with students, and checking in on the impact of IPV work on the students' world views.

\section{Relational}

On this level, the supervisor recognizes the importance of relational needs of students in helping to cope with trauma in several ways.

\section{Supportive Relationships}

Listening to the details of extreme violence may be one of the most crucial therapeutic interventions that social workers can provide for clients who have suffered from trauma (Hernandez-Wolfe et al. 2015). However, listening to these violent details can have negative effects on students. Supervisors who have open and positive relationships with students while normalizing their feelings of despair and hopelessness can have positive impacts on students (Peled-Avram 2017). A key role for a supervisor is to create opportunities for open discussion with students about the impacts of trauma, and issues that are upsetting to them (Berger et al. 2017). Supervisors are in unique positions as they can intervene at different times throughout field placements, which can ultimately impact students' well-being and their work with clients (Noble and Irwin 2009).

In some situations a student may not feel comfortable coming forward to a supervisor to discuss these issues. Therefore, it is the supervisor's responsibility to be observant and attuned to each student's emotional well-being. For instance, a supervisor might observe how a once energetic student may begin to show signs of disconnection or apathy towards her clients. The student may leave work early or avoid certain clients and frequently appear lethargic and tired, avoiding supervision and reporting that "everything is fine". These observations provide an opportunity for a supervisor to 'check in' with the student on her personal well-being, but also on her caseload of trauma clients.
Often, students with higher caseloads of clients experiencing trauma suffer from higher levels of secondary trauma themselves (Bober and Regehr 2006). Additionally, if a student does not feel comfortable discussing these issues in supervision, the supervisor can encourage her to debrief with her student peers or other staff members. Students, in particular, need a space to share their attitudes, perceptions, and emotional reactions while working with trauma clients. Students who experience indirect trauma and do not disclose it may feel anxiety, shame, and a sense of incompetence, and not seek supervision or additional support (Adams and Riggs 2008).

\section{Setting Boundaries}

Supervision can provide the necessary emotional support to monitor and detect signs of vicarious trauma and burnout. However, both supervisor and supervisee should also have firm boundaries between their professional and personal lives. Should the supervision become too personal, the supervisor might consider suggesting personal therapy (if appropriate) for additional support for the student. Supervisors can become excellent mentors and teachers but must maintain professional boundaries with their students. This can be challenging, but clarifying the role of supervision early in the relationship can help reinforce appropriate boundaries (Shaw 2013).

Discussions about boundaries within supervision can also provide a teaching moment around parallel processes, where the supervisor maintains boundaries with the student, emphasizing the importance of professional boundaries and their importance when working with clients (Peled-Avram 2017). Common boundary issues include sessions that last longer than the allotted time, extra phone calls or emails, and the student disclosing personal information or becoming "too friendly with clients". These are not uncommon issues, but a supervisor who is mindful of such boundaries in the supervisory relationship can help the student establish firm professional boundaries with their clients as well.

Also, drawing attention to the links between the student's past exposure to trauma and indirect trauma creates an additional need to pay attention to boundaries. Supervisors need to be cautious when approaching students about indirect trauma and engaging in dialogue that may result in a discussion of the student's previous history of trauma. For example, if the student has not been able to attend their own personal therapy they may have unresolved or unexamined issues of trauma that could emerge during supervision (Miehls 2010). The student may become overwhelmed with emotion if the supervisor makes the connection to personal trauma when the student has not been able to identify the relationship between their own trauma and their work with clients. A supervisor can provide some emotional support 
in the moment, but cannot take on the role as therapist. This would result in role confusion that could blur supervisor/ supervisee boundaries and ultimately impact the student's learning environment. Thus, some students should be encouraged to seek their own therapy to ensure that supervision does not turn into therapy.

\section{Discussions About Countertransference}

Supervision can be a supportive space where students can debrief about their cases and explore any personal responses to clients. This developmental perspective can help foster self-awareness and build more confidence in students (Bogo 2010). Countertransference is referred to as the conscious and unconscious reactions and feelings experienced in counseling sessions (Kadushin and Harkness 2002). Countertransference is often addressed in coursework but not always dealt with systematically in supervision. Countertransference may contribute to the indirect trauma of practitioners but it is different from indirect trauma (Harr and Moore 2011). Kudler (2011) suggests that many new therapists lack specific training in posttraumatic transference and countertransference due to insufficient supervision and training. Traumatic countertransference refers to a social worker's reactions during a session with a traumatized client (Berzoff and Kita 2010). Herman (1992) coined the term traumatic countertransference to describe the manner in which the previous trauma experienced by the practitioner and the exposure to trauma of clients can result in a form of traumatic enactment. Supervision can provide a safe space to process experiences of traumatic countertransference to ensure professional boundaries and self-care are maintained (Dekel and Baum 2009; Tosone et al. 2012).

\section{Community/Organizational}

There are specific strategies at an organizational and community level that supervisors can look to for ensuring students are adequately supported.

\section{Trauma Education and Training}

There is some literature that emphasizes the importance of specialized courses designed to prepare social work students for practice with trauma survivors (Abrams and Shapiro 2014; Agllias 2012; LeGeros and Savage Borne 2012). A pilot study of 258 BSW and MSW students found that students had a higher level of compassion fatigue than experienced professionals in the field (Harr and Moore 2011). These findings suggest that students working with trauma survivors may require more education about indirect trauma, including open discussions about compassion fatigue. The authors also recommend specific trauma training in social work curricula to better prepare students before and during field placements. While this learning may happen outside of the field setting, supervisors can build on these theoretical foundations by asking students to reflect on this course material, and can also ensure that students have access to trauma training and education within the field setting as well. Finally, regular supervision with a supervisor who is able to monitor for indirect trauma is also suggested.

In order to prepare students to be exposed to trauma within IPV settings, it is essential that social work programs offer specialized courses on IPV which include information on trauma. By focusing on topics such as trauma-informed practice, for instance, social work courses begin to prepare students to deal with indirect trauma, and provide the first step in creating a space where students can reflect on trauma (Harr and Moore 2011). When students learn to reflect on both their clients' and their own histories of trauma, they can improve their professional efficacy (Agllias 2012). In turn, when supervisors can then build on the trauma content of these courses in supervision, students can benefit within field placement settings.

In addition, organizations that provide weekly, or biweekly training early in field learning on trauma and selfcare can better prepare students for their work with clients (Breckenridege and James 2010). Moreover, offering additional opportunities for training in trauma-informed practice and other modalities (e.g., cognitive-behavioral therapy, trauma-focused cognitive-behavioral therapy, dialectical behavior therapy, and eye movement desensitization and reprocessing) should be also considered (Agllias 2012; Breckenridge and James 2010).

\section{Choice and Control}

While sometimes contradictory to the role of student, having choice in situations and feeling like one's voice is heard is key in trauma work (Berger et al. 2017). Supervisors can help by encouraging students to voice their needs and concerns, and by ensuring that they have adequate choice in the work they do and that their preferences related to their clients and caseloads are listened to (Berger et al. 2017). Berger et al. (2017) specifically suggest that supervisors "assign a trauma-related caseload that is balanced in severity, number, and types of clients' trauma, as well as take into account supervisees' length of professional experience and history of personal trauma" (p. 5). While this recommendation may be difficult to implement in some IPV settings, where most or all clients may be coping with some degree of trauma, it is still important for supervisors to attempt to provide some balance to trauma-related caseloads due to the concern that students are at a higher risk of indirect trauma when they have a large caseload of trauma clients (Knight 2013). Given that 
some clients may have experienced more severe trauma than others, it is recommended that supervisors attempt to be in-tune to these potential differences. In addition, supervisors can balance types of support supervisees are providing (e.g., mindfulness group sessions, intake counseling, individual counseling, applications or referrals for housing, financial assistance), to ensure variety and balance in exposure to trauma as much as possible.

\section{Organizational Support}

Commitment and support at the organizational level to the physical and emotional well-being of all practitioners and students is critical in dealing with indirect trauma (Harr and Moore 2011). Organizations can also provide supplementary support to help students during their field placement. Organizational initiatives that emphasize and prioritize selfcare among practitioners can be an important way to help students exposed to trauma (Berger et al. 2017). Supervisors can support students to attend workshops, self-care activities (e.g., lunchtime walks, breaks, yoga, etc), or advocate for student involvement in the creation of self-care initiatives during their field learning experiences.

\section{Structured Supervision}

Ultimately, regularly scheduled clinical supervision (e.g., weekly, bi-weekly) that is sensitive, systematic and directive is critical for student development and learning (Bogo 2010; Goldblaat and; Buchbinder 2003). Structured supervision gives supervisors an opportunity to modify caseloads, review professional boundaries, and assess for indirect trauma (Hesse 2002). Consistent, quality clinical supervision can also provide students with the opportunities to discuss their reactions to clients and their emotional responses which may protect them from indirect trauma (Kulkarni et al. 2013). Quality clinical supervision refers to supervision that is supportive, accessible, informative, and reciprocal. A supervisor providing quality supervision also possesses strong clinical skills (e.g., active listening, self-awareness, boundary setting, critical thinking) and provides clinical feedback that encourages students to reflect on complex cases (Bogo et al. 2011; Kulkarni et al. 2013).

\section{Structural/Environmental}

Looking outside the context of the agency to the broader environment, supervisors need to be aware of structural and societal influences on students, and their connections to experiences of indirect trauma.

\section{Stigma}

Social workers who disclose indirect trauma risk being perceived as weak or vulnerable and may be viewed as ineffective or inefficient. Stigma refers to broader institutional structures that devalue an individual's experiences of indirect trauma through internalized (e.g., shame towards personal experience of indirect trauma), perceived (e.g., awareness of negative societal attitudes towards indirect trauma), and enacted (subtle or overt responses from others in response to one's experience of indirect trauma) forms of stigma (Logie et al. 2017).

\section{Structural Empowerment}

Using a trauma-informed lens, it is important to help educate students on broader traumatic impacts in their lives (e.g., racism, classism, sexism, oppression, spiritual discrimination), in addition to previous experiences of abuse that they may expect to be triggered. At the structural level, supervisors can raise awareness of the potentially traumatic impacts of broader forms of oppression and traumatic events. As discussed by Tosone and colleagues (2003), shared trauma experienced from community and/or societal events can have powerful impacts on students, practitioners, and clients-illustrating the need for supervisors to be attuned to the potential traumatic impacts of broader societal events. Supervisors can empower students by engaging them in discussions about environmental events and impacts of oppression, and their relationship to indirect trauma. Additionally, an important area that needs further exploration within the literature is how supervisors can incorporate an intersectional lens to discuss ways in which students' identities and experiences of trauma may intersect in their lives, and impact their work in this area (Berger et al. 2017).

\section{Application of Framework Using Case Vignettes}

Case vignettes are used as a means of further discussing the impact of indirect trauma of students. These composite cases also help to illustrate a trauma-informed supervisory framework for students in IPV field placements.

\section{Case Vignette 1}

Raina is a 48-year old, married, heterosexual Southeast Indian woman with two children. She is in her first year of an MSW program in a medium size social work school in the United States. Raina is returning to university after a career in public relations and marketing. Her field placement is at an IPV counseling and advocacy agency that works with 
South Asian women who have experienced violence. She has individual supervision once every other week and group supervision with student peers once a month.

About a month into her field placement, Raina begins receiving referrals for counseling clients. After having an intake session with her fourth client, Raina became very emotional after realizing that she and the client had very similar backgrounds. The client recounted a detailed history of abuse as a child and as an adult, as well as a very traumatic experience immigrating to the United States. Following the session, Raina approached her supervisor and reported that the story was triggering to her and that she felt as though parts of her childhood were being re-enacted. The following week, Raina also reported feeling sad, tearful, and distracted at home.

During Raina's childhood, her mother was verbally and physically abused by her father. While Raina never directly witnessed the abuse, she heard the yelling and witnessed her mother's bruises. The abuse stopped when Raina was ten and her mother and father decided to stay together. Neither of Raina's parents ever addressed the abuse with Raina, who in turn carried this "secret" and feelings of shame and sadness. As an adult, Raina buried these memories and focused on having a healthy relationship with her husband and raising her own family. Years later, she decided she wanted to give back and help other women and children with similar experiences as hers. However, hearing women's stories of abuse began to wear her down and lead her to reconsider this choice.

\section{Supervisory Strategies}

This vignette illustrates the need for a supervisor to provide sufficient guidance and support to a mature social work student who is susceptible to experiencing shared trauma (primary and secondary trauma) based on her personal history of IPV and treating her client who also experienced IPV (see recommendations in Table 1). The supervisor also needs to be vigilant that professional boundaries and professionalism between supervisor and student are maintained. The supervisor could approach Raina in supervision by gently asking more about Raina's statements of "feeling triggered," and while normalizing feeling triggered when working with trauma survivors, linking the discussion to shared trauma and signs of indirect trauma that can occur among social workers. The supervisor could also ask if Raina would like to share more about aspects of her past that were causing her to feel triggered, and then encourage personal therapy for Raina for further support, depending on how much she discloses in supervision.

At this point, it would also be important for the supervisor to suggest increased supervision and formal/informal support (e.g., workshops or training on trauma, peer supervision

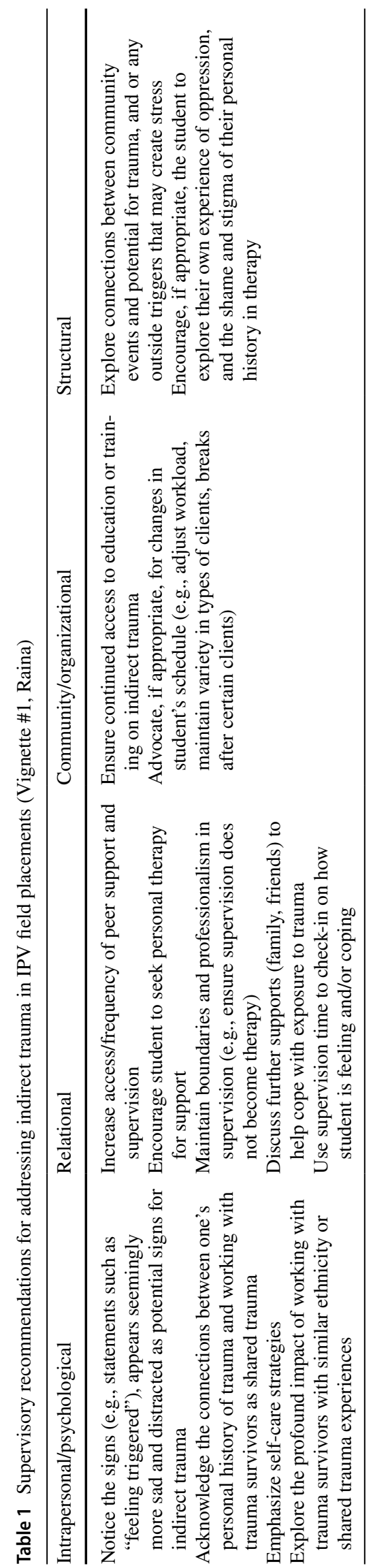


with other students, support from family or friends) while normalizing that this is a common occurrence for social workers to find that some clients are more "triggering" than others, and that many social workers share similar traumatic experiences as their clients. The supervisor can highlight the role of traumatic countertransference, and how meeting with this particular client has caused enactments of parts of Raina's childhood exposure to IPV, further describing the ways in which shared trauma can unconsciously and consciously cause personal distress. Providing this connection to her personal experiences of trauma in supervision can increase Raina's ability for enhanced self-awareness, insight, and reduce any feelings of shame. This is also an opportunity for the supervisor to emphasize the importance of self-care, and encourage Raina to develop her own self-care routines and strategies. The supervisor could then continue to monitor how Raina was feeling, and advocate for changes to her schedule and/or additional supports, as necessary.

\section{Case Vignette 2}

A social work student, Maya (age 24), is in her first year of an MSW program. Maya's field placement is in a large IPV organization in a large, metropolitan city in the United States. Maya is a white, heterosexual woman and enjoys a vibrant social life with friends and intimate partners. Maya comes from a middle-class family and has been an active volunteer in the community since she was a teenager, enjoying volunteering with children and older adults. As an undergraduate student, she became engaged in campus social justice groups and committees. At her field placement, Maya feels excited to work with women and children and hopes to make a difference. She has no previous experience working in the IPV field, or with survivors of trauma. Maya receives weekly individual supervision with her supervisor.

At first, Maya is enthusiastic about her busy caseload of clients and recently began running an IPV support group. In her spare time, Maya also begins attending films related to violence against women and joins IPV advocacy meet-ups. However, her usual social life, which includes friends who are not working in the IPV field, has decreased. Her dating life has also diminished, and she reports to her supervisor she has lost interest in dating. Despite Maya's high energy demeanor, over the course of several months, her supervisor notices her moods are less energetic, and she appears increasingly lethargic and sullen.

Maya is experiencing indirect trauma, specifically vicarious trauma brought on after a few months of repeated exposure to stories of trauma. She is experiencing a gradual shift in her cognitive thinking where her view of the world as a safe place has been altered. Although she once enjoyed a robust personal life with friends and dating partners, she now sees her friends less and reports not feeling safe with men intimately, after hearing so many stories of violence. Maya finds it hard to trust men and suspects that they may be abusive. She also feels her friends do not understand her or her work. Maya has experienced a profound shift in her identity, belief of self and others.

\section{Supervisory Strategies}

This example illustrates the need for a supervisor to provide sufficient guidance and support to a novice social worker who is susceptible to vicarious trauma (see recommendations in Table 2). Despite how the student presented initially (energetic, motivated, positive), Maya requires additional supervisory support. In particular, it is important that Maya's supervisor has provided education on vicarious and secondary trauma since the beginning of the placement, and then can continue to check in with Maya about whether she has noticed any changes in herself since beginning placement. Maya's supervisor could also generally discuss signs of vicarious trauma that social workers can experience, such as loss of energy or changes in relationships, and, depending on their supervisory relationship (e.g., openness, set boundaries), she could then ask whether Maya has experienced any of these signs. After learning what Maya has been experiencing, a key role of the supervisor is to ensure adequate support for Maya within and outside of the organization. In addition, the supervisor needs to ensure that any narratives of "shame" or "weakness" are discussed and challenged and replaced with discussions about the strength in coming forward to discuss the impacts of this work, and the need for further support and self-care.

\section{Conclusion}

This paper provides an initial framework for supervisors working with students in IPV field placements to cope with exposure to trauma. This paper responds to a gap in the literature in this area and a trend in social work practice to de-emphasize the role of supervision and to reduce access to quality clinical supervision despite increased demands of complex cases, including those who have experienced trauma (Berzoff and Drisko 2015). Given that supervision can mediate the effects of trauma on students in particular (Bell et al. 2003; Ben-Porat and Itzhaky 2011; Connor et al. 2012; Goldblatt and Buchbinder 2003; Harr and Moore 2011), it is crucial that more attention be paid to the supervision of social work students in IPV field placements. By instituting strategies at the individual/psychological, relational, community/organizational, and structural/environmental levels, supervisors can address and mitigate indirect trauma of social work students. Ultimately, these strategies 


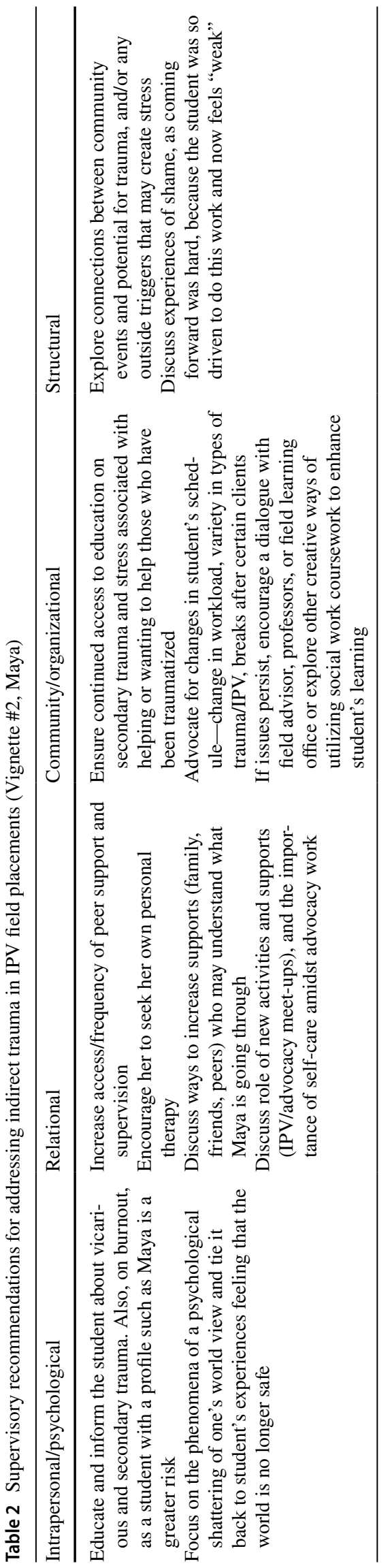

can help ensure our students are prepared for a successful future in the social work field.

Funding The authors received no financial support for the research, authorship, and/or publication of the article.

\section{Compliance with Ethical Standards}

Conflict of interest The authors declared no potential conflict of interest with respect to the research, authorship, and/or publication of this article.

Research Involving Human Participants This article does not contain any studies with human participants performed by any of the authors.

\section{References}

Abrams, J., \& Shapiro, M. (2014). Teaching trauma theory and practice in MSW programs: A clinically focused, case-based method. Clinical Social Work Journal, 42(4), 408-418. https://doi.org/10.1007/ s10615-013-0472-z.

Adams, S. A., \& Riggs, S. A. (2008). An exploratory study of vicarious trauma among therapist trainees. Training and Education in Professional Psychology, 2(1), 26-34. https://doi. org/10.1037/1931-3918.2.1.26.

Agllias, K. (2012). Keeping safe: Teaching undergraduate social work students about interpersonal violence. Journal of Social Work Practice, 26(2), 259-274.

Baird, S., \& Jenkins, S. R. (2003). Vicarious traumatization, secondary traumatic stress, and burnout in sexual assault and domestic violence agency staff. Violence and Victims, 18(1), 71-86.

Baral, S., Logie, C., Grosso, A., Wirtz, A. L., \& Beyrer, C. (2011). Modified social ecological model: A tool to guide the assessment of the risks and risk contexts of HIV epidemics. BMC Public Health, 13, 482. https://doi.org/10.1186/1471-2458-13-482.

Baum, N. (2013). Professionals' double exposure in the shared traumatic reality of wartime: Contributions to professional growth and stress. British Journal of Social Work, 24, 1-22.

Bell, H. (2003). Strengths and secondary trauma in family violence work. Social Work, 48(4), 513-522.

Bell, H., Kulkarni, S., \& Dalton, L. (2003). Organizational prevention of vicarious trauma. Families in Society: The Journal of Contemporary Social Services, 84(4), 463-470.

Ben-Porat, A., \& Itzhaky, H. (2011). The contribution of training and supervision to perceived role competence, secondary traumatization, and burnout among domestic violence therapists. The Clinical Supervisor, 30(1), 95-108.

Berger, R., Quiros, R., \& Benavidez-Hatzis, J. R. (2017). The intersection of identities in supervision for trauma-informed practice: Challenges and strategies. The Clinical Supervisor. https://doi. org/10.1080/07325223.2017.1376299.

Berzoff, J., \& Drisko, J. (2015). Preparing PhD-level clinical social work practitioners for the 21 st century. Journal of Teaching in Social Work, 35(1-2), 82-100. https://doi.org/10.1080/08841 233.2014.993107.

Berzoff, J., \& Kita, E. (2010). Compassion fatigue and countertransference: Two different concepts. Clinical Social Work Journal, 38, 341-349. https://doi.org/10.1007/s10615-010-0271-8.

Bober, T., \& Regehr, C. (2006). Strategies for reducing secondary or vicarious trauma: Do they work? Brief Treatment and Crisis Intervention, 6(1), 1-9. 
Bogo, M. (2010). Achieving competence in social work through field education. Toronto: University of Toronto Press - M.U.A..

Bogo, M., \& McKnight, K. (2006). Clinical supervision in social work. The Clinical Supervisor, 24(1-2), 49-67.

Bogo, M., Paterson, J., Tufford, L., \& King, R. (2011). Interprofessional clinical supervision in mental health and addiction: Toward identifying common elements. The Clinical Supervisor, 30(1), 124-140.

Bookchin, M. (1980). Toward an ecological society. Montreal: Black Rose.

Bookchin, M. (1982). The ecology of freedom: The emergence and dissolution of hierarchy. Palo Alto: Cheshire.

Breckenridge, J., \& James, K. (2010). Educating social work students in multifaceted interventions for trauma. Social Work Education, 29(3), 259-275.

Bride, B. E. (2004). The impact of providing psychosocial services to traumatized populations. Stress, Trauma, and Crisis, 7(1), 29-46.

Bride, B. E., Radey, M., \& Figley, C. R. (2007). Measuring compassion fatigue. Clinical Social Work Journal, 35(3), 155-163.

Bronfenbrenner, U. (1979). The ecology of human development: experiments by nature and design. Cambridge: Harvard University Press.

Byrne, M. K., Lerias, D., \& Sullivan, N. L. (2006). Predicting vicarious traumatization in those indirectly exposed to bushfires. Stress and Health, 22, 167-177. https://doi.org/10.1002/smi.1092.

Canfield, J. (2005). Secondary traumatization, burnout, and vicarious traumatization: A review of the literature as it relates to therapists who treat trauma. Smith College Studies in Social Work, 75(2), $81-101$.

Carello, J., \& Butler, L. D. (2015). Practicing what we teach: Trauma informed educational practice. Journal of Teaching in Social Work, 35, 262-278.

Center for Disease Control (2016). Intimate partner violence: Definitions. https://www.cdc.gov/violenceprevention/intimatepartner violence/definitions.html.

Center for Disease Control (2018). The social ecological model: A framework for intervention. https://www.cdc.gov/violenceprevent ion/overview/social-ecologicalmodel.html.

Chouliara, Z., Hutchison, C., \& Karatzias, T. (2009). Vicarious traumatisation in practitioners who work with adult survivors of sexual violence and child sexual abuse: Literature review and directions for future research. Counselling and Psychotherapy Research, 9(1), 47-56.

Connor, P. D., Nouer, S. S., Mackey, S. N., Banet, M. S., \& Tipton, N. G. (2012). Overcoming barriers in intimate partner violence education and training of graduate social work students. Journal of Teaching in Social Work, 32(1), 29-45.

Courtois, C. A. (2018). Trauma-informed supervision and consultation: Personal reflections. The Clinical Supervisor. https://doi. org/10.1080/07325223.2017.1416716.

Cunningham, M. (2003). Impact of trauma work on social work clinicians: Empirical findings. Social Work, 48(4), 451-459.

Dekel, R., \& Baum, N. (2009). Intervention in a shared traumatic reality: A new challenge for social workers. British Journal of Social Work, 40(6), 1927-1944

Didham, S., Dromgole, L., Csiernik, R., Karley, M. L., \& Hurley, D. (2011). Trauma exposure and the social work practicum. Journal of Teaching in Social Work, 31(5), 523-537. https://doi. org/10.1080/08841233.2011.615261.

Figley, C. R. (1983). Catastrophes: An overview of family reactions. In C. R. Figley \& H. I. McCubbin (Eds.), Stress and the family: Vol. 2. Coping with catastrophe (pp. 3-20). New York: Brunner/ Mazel.

Figley, C. R. (1995). Compassion fatigue: Towards a new understanding of the cost of caring. In B. H. Stamm (Ed.), Secondary traumatic stress: Self-care issues for clinicians, researchers, and educators (pp. 3-27). Lutherville: Sidran Press.

Figley, C. R. (Ed.). (2002). Treating compassion fatigue. New York: Brunner/Routledge.

Frey, L. L., Beesley, D., Abbott, D., \& Kendrick, E. (2017). Vicarious resilience in sexual assault and domestic violence advocates. Psychological Trauma: Theory, Research, Practice, and Policy, 9(1), 44.

Goldblatt, H., \& Buchbinder, E. (2003). Challenging gender roles: The impact on female social work students of working with abuse women. Journal of Social Work Education, 39(2), $255-275$.

Goodman, L. A., Sullivan, C. M., Serrata, J., Perilla, J., Wilson, J. M., Fauci, J. E., \& DiGiovanni, C. D. (2016). Development and validation of the trauma-informed practice scales. Journal of Community Psychology, 44, 747-764. https://doi.org/10.1002/ jcop.2016.44.issue-6.

Harr, C., \& Moore, B. (2011). Compassion fatigue among social work students in field placements. Journal of Teaching in Social Work, 31(3), 350-363.

Harris, M., \& Fallot, R. D. (2001). Using trauma theory to design service systems. San Francisco: Jossey-Bass.

Heise, L. L. (1998). Violence against women: An integrated, ecological framework. Violence Against Women, 4(3), 262-290.

Helms, J. E., Nicolas, G., \& Green, C. E. (2010). Racism and ethnoviolence as trauma: Enhancing professional training. Traumatology, 16(4), 53-62.

Herman, J. L. (1992). Trauma and recovery: The aftermath of violence-From domestic abuse to political terror. New York: Basic Books.

Hernandez-Wolfe, P., Killian, K., Engstrom, D., \& Gangsei, D. (2015). Vicarious resilience, vicarious trauma, and awareness of equity in trauma work. Journal of Humanistic Psychology, $55(2), 153-172$.

Hesse, A. R. (2002). Secondary trauma: How working with trauma survivors affects therapists. Clinical Social Work Journal, 30(3), 293-309.

Janof-Bulman, R. (1992). Shattered assumptions: Towards a new psychology of trauma. New York: The Free Press.

Jenkins, S. R., \& Baird, S. (2002). Secondary traumatic stress and vicarious trauma: A validational study. Journal of traumatic stress, 15(5), 423-432.

Jones, L., Hughes, M., \& Unterstaller, U. (2001). Post-traumatic stress disorder (PTSD) in victims of domestic violence: A review of the research. Trauma, Violence and Abuse, 2(2), 99-119.

Kadushin, A. (1992). What's wrong, what's right with social work supervision. The Clinical Supervisor, 10(1), 3-19.

Kadushin, A., \& Harkness, D. (2002). Supervision in social work. Columbia: University Press.

Knight, C. (2013). Indirect trauma: Implications for self-care, supervision, the organization, and the academic institution. The Clinical Supervisor, 32(2), 224-243.

Knight, C. (2015). Trauma-informed social work practice: Practice considerations and challenges. Clinical Social Work Journal, 43(1), 25-37.

Knight, C. (2018). Trauma-informed supervision: Historical antecedents, current practice, and future directions. The Clinical Supervisor. https://doi.org/10.1080/07325223.2017.1413607.

Kudler, H. (2011). Psychodynamic psychotherapy. In B. A. Moore \& W. E. Penk (Eds.), Treating PTSD in military personnel (pp. 107124). New York, London: The Guildford Press.

Kulkarni, S., Bell, H., Hartman, J. L., \& Herman-Smith, R. L. (2013). Exploring individual and organizational factors contributing to compassion satisfaction, secondary traumatic stress, and burnout in domestic violence service providers. Journal of the Society for Social Work and Research, 4(2), 114-130. 
LeGeros, M., \& Savage Borne, J. (2012). Building bridges: Training social work students in domestic violence work. Field Educator, 2(2), 1-16.

Litvack, A., Mishna, F., \& Bogo, M. (2010). Emotional reactions of students in field education: An exploratory study. Journal of Social Work Education, 46(2), 227-243. https://doi.org/10.5175/ JSWE.2010.200900007.

Logie, C. H., Alaggia, R., \& Rwigema, M. J. (2014). A social ecological approach to understanding correlates of lifetime sexual assault among sexual minority women in Toronto, Canada: Results from a cross-sectional internet-based survey. Health Education Research, 29(4), 671-682.

Logie, C. H., Lacombe-Duncan, A., Levermore, K., \& Jones, N. (2017). Conceptualizing empowerment practice with lesbian, gay, bisexual and transgender youth in Jamaica. Social Work Education, 36(4), 456-465.

Maslach, C. (1982). Understanding burnout: Definitional issues in analyzing a complex phenomenon. In W. S. Paine (Ed.), Job stress and burnout: Research, theory, and intervention perspectives (pp. 29-40). Beverly Hills: SAGE.

Miehls, D. (2010). Contemporary trends in supervision theory: A shift from parallel process to relational and trauma theory. Clinical Social Work Journal, 38(4), 370-378.

National Network to End Domestic violence. (2016). National Census of Domestic Violence Services Report Summary. https://www. nnedv.org/mdocs-posts/census_2016_handout_national-summa ry/.

Noble, C., \& Irwin, J. (2009). Social work supervision. Journal of Social Work, 9(3), 345-358. https://doi.org/10.1177/1468017309 334848.

Pearlman, L. A., \& Saakvitne, K. W. (1995). Trauma and the therapist: countertransference and vicarious traumatization in psychotherapy with incest survivors. New York: W.W. Norton.

Peled-Avram, M. (2017). The role of relational-oriented supervision and personal and work-related factors in the development of vicarious traumatization. Clinical Social Work Journal, 45(1), 22-32.

Pill, N., Day, A., \& Mildred, H. (2017). Trauma responses to intimate partner violence: A review of current knowledge. Aggression and Violent Behavior, 34, 178-184.

Rasmussen, B. (2012). The effects of trauma treatment on the therapist. In S. Ringel \& J. Brandell (Eds.), Trauma: Contemporary directions in theory, practice, and research (pp. 223-247). Thousand Oaks: SAGE Publications, Inc.

Shaw, E. (2013). Mentoring or monitoring: Formulating a balance in systemic supervision. Australian and New Zealand Journal of Family Therapy, 34(4), 296-310.
Slattery, S. M., \& Goodman, L. A. (2009). Secondary traumatic stress among domestic violence advocates: Workplace risk and protective factors. Violence Against Women, 15(11), 1358-1379.

Sommer, C. A. (2008). Vicarious traumatization, trauma-sensitive supervision, and counselor preparation. Counselor Education and Supervision, 48(1), 61-71.

Stokols, D., Lejano, R., \& Hipp, J. (2013). Enhancing the resilience of human-environment systems: A social ecological perspective. Ecology and Society, 18(1), 1-12.

Straussner, S. L. A., \& Calnan, A. J. (2014). Trauma through the life cycle: a review of current literature. Clinical Social Work Journal, 42(4), 323-335.

Tosone, C., Lee, M., Bialkin, L., Martinez, A., Campbell, M., Martinez, M. M., et al. (2003). Shared trauma: Group reflections on the September 11th disaster. Psychoanalytic Social Work, 10(1), $57-77$.

Tosone, C., McTighe, J. P., \& Bauwens, J. (2014). Shared traumatic stress among social workers in the aftermath of Hurricane Katrina. British Journal of Social Work, 45(4), 1313-1329.

Tosone, C., Nuttman-Shwartz, O., \& Stephens, T. (2012). Shared trauma: When the professional is personal. Clinical Social Work Journal, 40, 231-239. https://doi.org/10.1007/s1061 5-012-0395-0.

Trevillion, K., Oram, S., Feder, G., \& Howard, L. M. (2012). Experiences of domestic violence and mental disorders: A systematic review and meta-analysis. PLOS ONE, 7, e51740.

Ungar, M. (2002). A deeper, more social ecological social work practice. Social Service Review, 76(3), 480-497.

Sarah Tarshis is a PhD candidate at the Faculty of Social Work, University of Toronto. Sarah's research interests include intimate partner violence (IPV), employment, empowerment/resilience, and traumainformed practice. Her doctoral project focuses on the experiences of employment-seeking survivors of IPV and is informed by ten years of social work practice.

Stephanie L. Baird MSW, RSW, $\mathrm{PhD}$, is a social worker whose research interests focus on trauma, intimate partner violence, and social work education (both in the field and in the classroom). Her research interests have been informed by over 15 years of clinical social work experience. 